\title{
Pengenalan Sistem Pertanian Organik Melalui Penyuluhan Pada Gabungan Kelompok Tani (Gapoktan) di Desa Tempos Kecamatan Gerung Lombok Barat
}

\author{
Baiq Azizah Haryantini*, I Made Sunantra \\ Fakultas Pertanian Universitas 45 Mataram, \\ Jalan Imam Bonjol Cakranegara Kota Mataram NTB
}

\section{Article history}

Received: 15-10-2020

Revised: 20-11-2020

Accepted: 25-11-2020

*Corresponding Author:

Baiq Azizah Haryantini,

Fakultas Pertanian Universitas 45

Mataram, Mataram

Nusa Tenggara Barat, Indonesia

Email:

b_azizah_haryantini@upatma.ac.id

\begin{abstract}
Aim of Community service activities, namely counse to explain and invite farmers in Tempos Village Gerung District, West Lombok Regency, to be familiar with the implementation of the organic farming system, and encourage farming communities to utilize the potential of natural resources well and wisely to protect agricultural land from degradation (damage) and good production in the long term. For this reason, counseling has been carried out in the agricultural sector, namely the organic farming system with the results of farmers and the community understands that the organic farming system has the potential to be implemented on agricultural land in the village of Tempos, and to improve soil health and protect the environment from degradation (damage) in the long term (sustainable). Farmers are motivated to improve their ability to manage their farming with an organic farming system.
\end{abstract}

Keywords: counseling; organic; farming; sustainable

Abtrak: Kegiatan pengabdian kepada masyarakat, yaitu penyuluhan system pertanian organik di Desa Tempos Kecamatan Gerung Kabupaten Lombok Barat, bertujuan untuk menjelaskan serta mengajak masyarakat/petani mengenal dengan baik pelaksanaan system pertanian organik, dan mendorong masyarakat petani dalam memanfaatkan potensi sumber daya alam yang dimiliki secara baik dan arif untuk menjaga lahan pertanian dari degradasi (kerusakan) dengan produksi yang baik dalam jangka waktu panjang. Untuk itu telah dilakukan penyuluhan bidang pertanian yaitu system pertanian organik dengan hasil petani dan masyarakat memahami bahwa system pertanian organik berpotensi dilaksanakan di lahan pertanian Desa Tempos, untuk perbaikan kesehatan tanah dan menjaga lingkungan dari degradasi (kerusakan) dalam waktu jangka panjang (sustainable). Petani termotivasi untuk meningkatkan kemampuan mengelola usaha taninya dengan sistem pertanian organik.

Kata Kunci: berkelanjutan; penyuluhan; pertanian; organik

\section{PENDAHULUAN}

Luas lahan pertanian di Desa Tempos Kecamatan Gerung Lombok barat adalah 552 Hektar, dengan luas total lahan pertanian $334 \mathrm{Ha}$, ini terbagi dalam areal sawah $300 \mathrm{Ha}$, lahan kebun/tegalan 34 Ha (sumber: UPTD Pertanian Kecamatan Gerung LOBAR). Lahan pertanian tersebut diolah oleh petani yang tergabung dalam Gabungan Kelompok Tani (GAPOKTAN) berjumlah 12 kelompok, 
terbagi dalam 12 GAPOKTAN pangan, 5 GAPOKTAN ternak, 1 GAPOKTAN Kebun dan 1 Kelompok Wanita Tani (KWT).

Praktek budidaya yang dilakukan oleh masyarakat tani desa Tempos masih bersifat konvensional, dengan pola tanam padi - padi - palawija (kedelai atau jagung). Pemupukan yang dianjurkan pada petani yaitu rekomendasi pemupukan berimbang 5:3:2, yaitu pupuk organik (granul), NPK (15:15:15), UREA (sumber: informasi dari PPL). Tetapi banyak petani yang tidak laksanakan pemupukan sesuai anjuran, dan lebih banyak gunakan pupuk kimia/anorganik secara tidak seimbang. Jika hal ini terus dilakukan dalam waktu lama dapat mengakibatkan penurunan kesuburan tanah. Pertanian konvensional pada tahap-tahap awal mampu meningkatkan produktivitas pertanian secara nyata, akan tetapi dalam jangka panjang, efisiensi produksi semakin menurun karena berbagai efek samping yang merugikan seperti penurunan kesuburan tanah dan kehilangan bahan organik tanah, akibatnya tanah tidak sehat (Simarmata et al. 2017).

Disamping itu di desa Tempos terdapat potensi pengelolaan ternak, dengan limbah kotoran hewan yang bisa dimanfaatkan sebagai bahan pupuk organik yang jika dikelola dengan baik, sebenarnya bisa menunjang pelaksanaan pertanian organik, sehingga dapat mengatasi permasalahan kebutuhan pupuk yang pada akhirnya akan dapat membantu mengatasi masalah degradasi lahan akibat penggunaan pupuk kimia secara terus menerus (Roidah 2013).

Oleh karena itu tujuan dari penyuluhan ini dilaksanakan untuk menjelaskan serta mengajak petani di Desa Tempos mengenal dengan baik pelaksanaan dan tatacara pertanian organik. Penyuluhan dilaksanakan di Desa Tempos ini karena memungkinkannya potensi pelaksanaan praktik pertanian organik karena masih terdapat banyak potensi sumberdaya lahan pertanian yang masih subur (belum terdegradasi), disamping itu adanya kandang kolektif ternak yang dimiliki warga yang bisa sebagai sumber pupuk organik. Penggunaan pupuk dan pestisida kimia di Desa Tempos yang masih tinggi yang bisa memberikan dampak buruk bagi kesuburan tanah dan lingkungan. Alasan kuat lain diadakannya penyuluhan ini adalah tingginya motivasi dan aspirasi masyarakat untuk mengadopsi dan menerapkan tehnologi system pertanian organik untuk meningkatkan produksi pertaniannya.

Berdasarkan hal tersebut, setelah dilakukannya penyuluhan ini, diharapkan adanya tanggapan para peserta /petani bertambahnya wawasan, pemahaman dan sikap positif peserta terutama petaniterhadap potensi pengelolaan budidaya pertanian dengan sistem organik. Tumbuhnya antusiasme dari peserta/petani untuk meningkatkan kemampuan mengelola usaha taninya dengan sistem pertanian organik.

\section{METODE}

Penyuluhan ini terselenggara atas kerja sama 1) Fakultas Pertanian Universitas 45 Mataram, 2) Perangkat desa Tempos 3) Penyuluh Pertanian Lapangan Desa Tempos. Peserta penyuluhan adalah petani perwakilan dari seluruh Gapoktan dan KWT yang ada di Desa Tempos. Kegiatan yang dilaksanakan dalam program ini meliputi: 1) Tahap persiapan, yang meliputi koordinasi tim pelaksana, koordinasi dengan Pemerintah Desa dan anggota kelompok tani yang diikutsertakan dalam kegiatan pengabdian masyarakat ini, 2) Program meliputi kegiatan penyuluhan dan diskusi 3) Evaluasi dan pembuatan laporan hasil kegiatan. Tempat dan waktu: penyuluhan ini bertempat di Aula Desa Tempos dan dilaksanakan pada hari Kamis tanggal 13 Agustus 2020 pada jam 09.00 wita sampai dengan selesai. Metode Pelaksanaan yang digunakan dalam kegiatan pengabdian pada masyarakat ini adalah 
metode ceramah dan dilengkapi dengan power point, dan selanjutnya dilakukan tanya jawab dan diskusi.

\section{HASIL DAN PEMBAHASAN}

Kegiatan penyuluhan ini adalah kegiatan pengabdian masyarakat dari para dosen Fakultas Pertanian dan Fakultas Hukum Universitas 45 Mataram. Kegiatan ini didukung penuh oleh perangkat Desa Tempos dan dibantu koordinasi bersama penyuluh pertanian lapangan (PPL) yang bertugas di desa Tempos sehingga peserta siap hadir pada waktu yang telah ditentukan.

Penyuluhan berlangsung lancar, dengan metode ceramah dilengkapi dengan power point sehingga pada saat penyampaian materi para peserta menjadi mengerti dan ada gambaran bagaimana system pertanian organik.

Penyampaian materi tentang pertanian organik disampaikan dengan menjelaskan materi yang telah dipersiapkan oleh para dosen secara singkat dan disampaikan secara jelas. Adapun materi yang disampaikan antara lain Pertanian organik adalah sistem budi daya pertanian yang mengandalkan bahan-bahan alami tanpa menggunakan bahan kimia sintetis (Riwandi 2010). Pertanian organik adalah sistem pertanian yang holistic (menyeluruh) yang mendukung dan mempercepat biodiversiti, siklus biologi dan aktivitas biologi tanah termasuk produk organik yang dihasilkan, penyimpanan, pengolahan, pasca panen dan pemasaran harus sesuai standar yang ditetapkan oleh badan standardisasi (Mayrowani 2016). Pengolahan pertanian organik didasarkan pada prinsip kesehatan, ekologi, keadilan, dan perlindungan. Prinsip kesehatan dalam pertanian organik adalah kegiatan pertanian harus memperhatikan kelestarian dan peningkatan kesehatan tanah, tanaman, hewan, bumi, dan manusia sebagai satu kesatuan karena semua komponen tersebut saling berhubungan dan tidak terpisahkan.

Contoh praktik prinsip kesehatan pada pertanian organik yaitu menggunakan pestisida alami dan pupuk alami, rotasi tanaman, pupuk hijau/kompos, pengendalian hama secara biologis, dan pengolahan tanah secara mekanis.

Pertanian organik menghasilkan daging, susu, telur secara organik melalui pemeliharaan hewan ternak akan menjadi pelengkap bagi usaha pertanian organik. Kuda dan sapi dapat menjadi hewan pekerja yang menyediakan tenaga untuk menggerakkan mesin, membajak, menambah kesuburan tanah dengan kotorannya, dan menjadi sumber bahan bakar (misal biogas).

Petani konvensional yang memiliki lahan yang telah terbiasa menggunakan pupuk kimia, tidak berarti tidak bisa beralih menjadi petani organik. Disisi lain petani dituntut memenuhi kebutuhan dan keharusan produksi tinggi untuk lahannya. Langkah langkah yang perlu dilakukan adalah perbaikan kondisi tanahnya dengan cara mengurangi penggunaan pupuk kimia sedikit demi sedikit. Beberapa penelitian menunjukkan perbandingan pemberian pupuk organik di tanah tidak memberikan respon positif dibandingkan dengan pupuk kimia anorganik (Mayrowani 2016). Hal ini dapat dimengerti karena pupuk organik termasuk slow release dan membutuhkan waktu cukup lama untuk perbaikan kondisi tanah.

Karena pada dasarnya jika petani sebagai pelaku pertanian organik menerapkan seluruh prinsip dasar dan poin poin pelaksanaan inti dalam pertanian organik maka kesuburan tanah akan terjaga dengan baik, hasil tanaman yang dibudidayakan secara organik dapat menghasilkan pertumbuhan yang optimal.

Pada saat sesi diskusi, beberapa petani bertanya yang dirangkum seperti dibawah ini: 
1. Bagaimana cara merubah dari pertanian yang sekarang dilakukan (konvensional) ke system pertanian organik, karena ada kekhawatiran jika beralih maka produksi lahannya akan menurun.

2. Bagaimana cara membuat pupuk organik

3. Di desa Tempos banyak terdapat limbah kotoran hewan (kohe) sapi karena ada beberapa kandang kolektif, bagaimana cara memanfaatkan?

Pertanyaan pertanyaan peserta ini kemudian dijawab dengan singkat dan jelas:

1. Bahwa peralihan pertanian konvensional ke pertanian organik bisa dilakukan, dengan cara mengurangi penggunaan pupuk kimia sedikit demi sedikit dan mulai menambahkan bahan organik seperti kompos dan pupuk organik yang bisa diproduksi sendiri oleh petani. Hal ini dilakukan agar produksi pada lahannya tidak turun dengan drastis tetapi langkah ini bisa membuat perbaikan kondisi lahan dalam jangka waktu panjang.

2. Pembuatan pupuk organik bisa dilakukan dengan memanfaatkan bahan bahan organik yang ada di desa Tempos, seperti kompos dari sisa jerami dan limbah pertanian lainnya, demikian juga dengan memanfaatkan kohe sapi yang banyak terdapat di desa Tempos karena adanya kandang kolektif di Gapoktan Ternak.

3. Limbah kohe sapi yang sangat berlimpah di desa Tempos, untuk penanganan cepat dianjurkan untuk membuat lubang di tanah untuk tempat menampung kohe sapi, setelah penuh kemudian ditutup dengan tanah yang digali dari lubang yang baru, demikian seterusnya. Setelah kohe berubah warna dan strukturnya sudah seperti tanah, bisa di ayak dan kemudian dikemas dalam karung. Kohe ini akan sangat laku dijual untuk media penanaman tanaman hias. Solusi ini adalah cara praktis diberikan kepada Gapoktan ternak, karena pernah dilakukan untuk produksi biogas, tetapi maintenance dan keberlanjutannya terkendala.

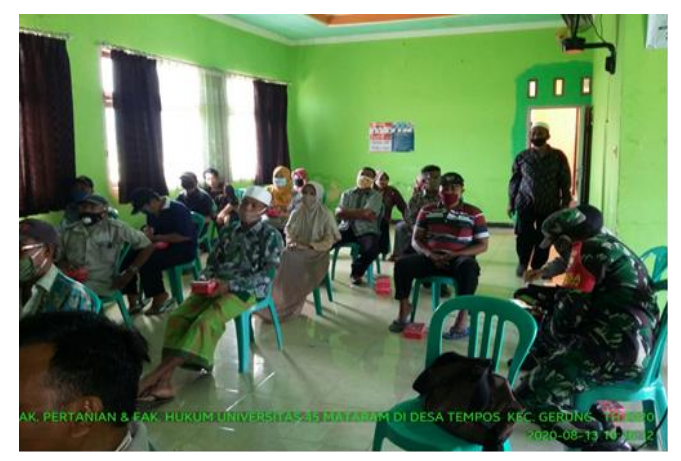

Gambar 1. Suasana diskusi, dimana salah satu peserta (berdiri) sedang ajukan pertanyaan

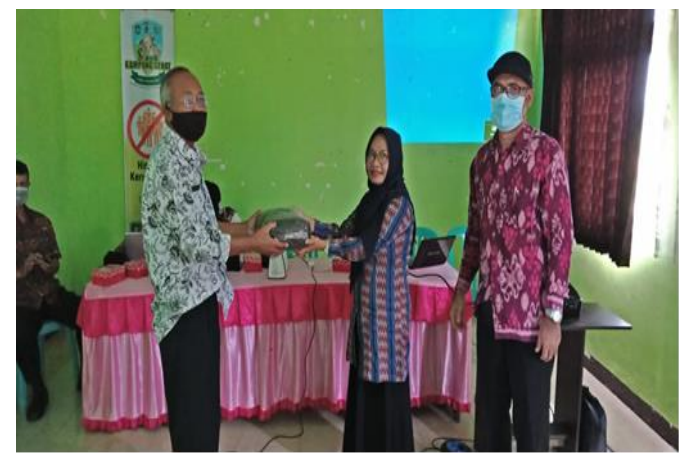

Gambar 2. Penyerahan kompos yang sudah dikemas, sebagai salah satu contoh produk organik, yang diberikan secara simbolis kepada petani

Kegiatan penyuluhan ini merupakan salah satu motivasi masyarakat Desa Tempos untuk lebih memahami system pertanian organik. Tanggapan dari masyarakat tani yang begitu antusias dalam mengikuti penyuluhan ini menggambarkan bahwa potensi pelaksanan system pertanian organik bisa dilakukan. Di Desa Tempos ini telah terbentuk Gabungan Kelompok Tani (GAPOKTAN) sesuai dengan komoditi yang dikelolanya, hal ini menjadi 
potensi wadah yang baik untuk mengenalkan dan aplikasikan system pertanian organik di usaha taninya. Melalui GAPOKTAN ini langkah awal dengan cara menerapkan system pertanian organik yang akan menjadi contoh bagi petani lain.

Misalnya saja pada GAPOKTAN sayuran, mulai dari pengurangan dosis pupuk kimia, dan persiapan lahan dengan pupuk dasar yang berasal dari pupuk kandang, system budidaya ini akan memberikan tingkat keberhasilan cukup tinggi maka petani lain akan mudah mencontohnya, kelompok tani semacam ini dapat meningkatkan perilaku petani kearah yang lebih baik dalam meningkatkan pendapatan petani. Sosialisasi budidaya organik kepada petani sayuran bertujuan untuk memotivasi petani memanfaatkan lahan dengan diusahakannya tanaman sayuran secara organik sehingga dapat meningkatkan produktivitas lahan yang akan berdampak pada peningkatan pendapatan Selain itu faktor social, faktor ekonomi, faktor tehnologi, faktor sumberdaya, faktor kelembagaan dan faktor budaya juga berperan penting dalam meningkatkan pendapatan petani (Rasmikayati and Saefudin 2018).

Kendala penerapan system pertanian organik adalah adanya kekhawatiran petani akan rendahnya hasil pertaniannya, karena memang bahan organik bersifat slow release (Rahmawati 2006) atau lambatnya penguraian sehingga dirasa lambat untuk meningkatkan produktivitas, dalam hal ini petani harus diberi pemahaman yang mendalam bahwa system pertanian organik bertujuan menyelamatkan penggunaan lahan dalam jangka panjang, dalam diskusi di penyuluhan ini juga dijelaskan bagaimana mempercepat bahan organik dari limbah pertanian dapat dimanfaatkan untuk kompos. Seperti diketahui bahwa kompos adalah hasil penguraian dari campuran bahan-bahan organik yang dapat dipercepat secara artifisial oleh populasi berbagai macam mikroba dalam kondisi lingkungan yang hangat, lembap, dan aerobik atau anaerobik(Mayrowani 2016), dengan penjelasan ini para petani paham bahwa limbah pertanian yang selama ini belum termanfaatkan maksimal ternyata dapat dimanfaatkan.

Antusias para petani yang menjadi peserta penyuluhan ini juga mengusulkan agar ada pendampingan penerapan pelaksanaan system pertanian organik di desa Tempos, mulai dari praktik pembuatan kompos dari limbah pertanian, juga pendampingan pengelolaan limbah kotoran hewan dan praktik pertanian organik lainnya,

\section{KESIMPULAN DAN SARAN}

Berdasarkan kegiatan penyuluhan yang sudah dilaksanakan dapat disimpulkan bahwa Petani dan masyarakat Desa Tempos Kecamatan Gerung Kabupaten Lombok Barat memahami bahwa system pertanian organik berpotensi dilaksanakan di lahan pertanian desa Tempos, untuk perbaikan kesehatan tanah dan menjaga lingkungan dari degradasi (kerusakan) dalam waktu jangka. Petani termotivasi untuk meningkatkan kemampuan mengelola usaha taninya dengan sistem pertanian organik.

\section{Ucapan Terima Kasih}

Terimakasih kami ucapkan kepada Universitas 45 Mataram yang telah memberikan izin sehingga kegiatan penyuluhan ini dapat dilaksanakan, terimakasih pula kami sampaikan kepada Bapak Kepala Desa Tempos dan aparatnya, serta PPL Desa Tempos, para petani yang tergabung dalam Gapoktan dan KWT yang telah mendukung terselenggaranya kegiatan ini dengan baik. 


\section{DAFTAR PUSTAKA}

Mayrowani, Henny. 2016. "Pengembangan Pertanian Organik Di Indonesia." Forum penelitian Agro Ekonomi 30(2): 91.

Rahmawati, Nini. 2006. "Pemanfaatan Biofertilizer Pada Pertanian Organik." Universitas Sumatera Utara.

Rasmikayati, Elly, and Bobby Rachmat Saefudin. 2018. "Analisis Faktor-Faktor Yang Mampu Mendorong Petani Pada Era Globalisasi.” Paradigma Agribisnis 1(September): $1-13$.

Riwandi. 2010. "IDENTIFIKASI DAN INTERPRETASI INDIKATOR KESEHATAN TANAH Oleh.” In Jambi.

Roidah, Ida Syamsu. 2013. "MANFAAT PENGGUNAAN PUPUK ORGANIK UNTUK KESUBURAN TANAH." 1(1).

Simarmata, Tualar, Tien Turmuktini, Betty N Fitriatin, and Mieke R Setiawati. 2017. "Application of Bioameliorant and Biofertilizers to Increase the Soil Health and Rice Productivity." HAYATI Journal of Biosciences 23(4): 181-84. http://dx.doi.org/10.1016/j.hjb.2017.01.001. 